\title{
Cl-Orbitrap : An Analytical Instrument To Study Atmospheric Reactive Organic Species
}

Riva, M.

2019-08-06

Riva , M , Ehn , M , Li , D , Tomaz , S , Bourgain , F , Perrier , S \& George , C 2019 , '

Cl-Orbitrap : An Analytical Instrument To Study Atmospheric Reactive Organic Species ' ,

Analytical Chemistry , vol. 91 , no. 15 , pp. 9419-9423 . https://doi.org/10.1021/acs.analchem.9b02093

http://hdl.handle.net/10138/318167

https://doi.org/10.1021/acs.analchem.9b02093

acceptedVersion

Downloaded from Helda, University of Helsinki institutional repository.

This is an electronic reprint of the original article.

This reprint may differ from the original in pagination and typographic detail.

Please cite the original version. 


\title{
CI-Orbitrap: An Analytical Instrument to Study Atmospheric Reactive Organic Species
}

\author{
M. Riva ${ }^{*},{ }^{\dagger}$, M. Ehn ${ }^{\ddagger}$, D. Li ${ }^{\dagger}$, S. Tomaz ${ }^{\dagger}$, F. Bourgain ${ }^{\dagger}$, S. Perrier ${ }^{\dagger}$, C. George ${ }^{\dagger}$ \\ $\dagger$ Univ Lyon, Université Claude Bernard Lyon 1, CNRS, IRCELYON, F-69626, Villeurbanne, France. \\ \$ Institute for Atmospheric and Earth System Research / Physics, Faculty of Science, FI-00014 University of Helsinki, \\ Helsinki, Finland.
}

KEYWORDS Highly Oxygenated Molecules (HOM), organic aerosol, OVOC, CIMS, CI-APi-TOF

\begin{abstract}
While acknowledged as key components in the formation of new particles in the atmosphere, the accurate characterization of gaseous (highly) oxygenated organic compounds remains challenging, and requires analytical developments. Earlier studies have successfully used the nitrate ion $\left(\mathrm{NO}_{3}^{-}\right)$based chemical ionization $(\mathrm{CI})$ coupled to atmospheric pressure interface time-of-flight mass spectrometry (CI-APi-TOF) for monitoring these compounds. Despite many breakthroughs in recent years, the CI-APi-TOF has many limitations, preventing for instance the unambiguous ion identification of overlapping peaks. To tackle this analytical challenge, we developed a CI interface coupled to an ultrahigh-resolution Orbitrap mass spectrometer (CI-Orbitrap). We show that the CI-Orbitrap has similar sensitivity and selectivity as the CI-APi-TOF, but with over an order of magnitude higher mass resolving power (up to 140 000). Equally importantly, the CI-Orbitrap allows tandem mass spectrometry, providing the first possibility for structural elucidation of the highly oxygenated molecules (HOM). As a proof of concept, we characterized HOM formed during the ozonolysis of two biogenic compounds ( $\alpha$-pinene and limonene), under different environmental conditions in a flow reactor. The CI-Orbitrap exhibited high sensitivity to both HOM and radical species, while easily separating ions of different elemental composition in cases where the more common TOF applications would not have been able to distinguish all ions. Our tandem mass spectrometry analyses revealed distinct fingerprint spectra for all the studied HOM. Overall, the CI-Orbitrap is an extremely promising instrument, and it provides a much-needed extension to on-going research on HOM, with potential to impact also many other fields within atmospheric chemistry.
\end{abstract}

Atmospheric aerosols, a mixture of solid and liquid particles of organic and inorganic substances suspended in the air, make up less than a millionth of a percent of the atmosphere, yet they still produce a significant cooling effect on our planet. They do this in two ways: by directly reflecting solar radiation back into space, and by acting as nuclei for cloud droplet formation, whereby they regulate cloud reflectivity and lifetimes. ${ }^{1,2}$ Typically, only particles larger than $100 \mathrm{~nm}$ in diameter result in cloud condensation nuclei, and therefore the chemical components and the processes contributing to the growth of such particles are extremely important. Atmospheric aerosols are also recognized to adversely impact air quality and human health, representing nowadays the fifth-ranking human health risk factor, globally. ${ }^{3}$

Depending on the geographic region, organic aerosol on average contributes $20-90 \%$ to the submicron aerosol mass, ${ }^{4}$ with secondary organic aerosol (SOA) as the largest source of atmospheric organic aerosol. ${ }^{4,5}$ The organic vapors able to grow aerosols by gas-to-particle conversion, thus forming SOA, are primarily formed through the oxidation of volatile organic compounds (VOC), yielding a wide variety of oxygenated VOC (OVOC). ${ }^{5}$ Characterization of all these OVOC represents a unique analytical challenge. ${ }^{6,7}$ Over the last five years, major breakthroughs have been achieved within the field of atmospheric oxidation processes and aerosol particle formation..$^{8-11}$ A pivotal starting point was the identification of highly oxygenated organic molecules (HOM), ${ }^{8}$ formed through a process called autoxidation ${ }^{12}$. In this process, peroxy radicals formed from the oxidation of a VOC undergo intramolecular hydrogen abstraction, followed by the addition of molecular oxygen. This results in the formation of a new peroxy radical, with an additional hydroperoxyl group. This chain reaction can be repeated and lead to a wide variety of products depending on the termination mechanisms. ${ }^{11}$ HOM have been shown to contribute to the nucleation and growth of new particles both in atmospheric simulation chambers and in the atmosphere. ${ }^{11,13}$ However, a complete understanding of how VOC oxidation processes contribute to new particle and SOA formation is still lacking, and the quantitative evaluation of the impact of aerosol on air quality and climate remains poorly understood. ${ }^{6}$

Over the last ten years, mass spectrometric techniques have made dramatic improvements in detecting and characterizing gas-phase oxygenated species, including radicals, of varying volatilities. $^{14,15}$ In particular, chemical ionization mass spectrometry (CIMS) has emerged as a powerful tool to characterize a wide range of different gaseous compounds. ${ }^{11,16-}$

${ }^{18} \mathrm{CI}$ is a soft ionization technique where the analyte is ionized through clustering process with the reagent ions and undergoes only minimal fragmentation. ${ }^{17,19,20}$ While CIMS provides very good sensitivities (detection limit as low as $10^{4}$ molecules $\mathrm{cm}^{-}$ $\left.{ }^{3}\right),{ }^{19}$ they are commonly coupled to TOF mass analyzers having limited mass resolving power. This typically ranges from 4000 for a medium-resolution (e.g., the Tofwerk AG HTOF) to 14 000 for a high-performance TOF (e.g., Tofwerk AG LTOF). ${ }^{16}$ These resolving powers make identification and quantification of individual organic molecules extremely challenging in cases with multiple overlapping ions, yielding significant uncertainties. 16,21,22 Indeed, "atmospheric" mass spectra acquired using the CIMS technique typically contain a large amount of information, and therefore remain complex in nature, 
representing a significant challenge for data analysis. Computational approaches, including ion deconvolution procedures, are required to solve this limitation in order to extract the maximum possible information content. ${ }^{21,23}$ In addition, as the primary method to detect HOM has hitherto been based on the chemical ionization atmospheric pressure interface time-of-flight mass spectrometry (CI-APi-TOF), ${ }^{19}$ there is no more information to be obtained beside the elemental composition. Therefore, very little is known about their structures and/or their physicochemical properties (e.g., volatility).

In this work, we successfully coupled a high-resolution mass spectrometer (Orbitrap) with a CI source to overcome many current instrumental limitations. The CI-Orbitrap combines the benefits of soft atmospheric pressure ionization, high mass resolving power $(\mathrm{R}=140000$ at $\mathrm{m} / \mathrm{z} 200)$ and high time resolution ( $\sim 10$ seconds). As a proof of concept, we analyzed gas-phase OVOC formed during the oxidation of two monoterpenes using nitrate-ion-based $\left(\mathrm{NO}_{3}{ }^{-}\right) \mathrm{CI}$. We used this chemistry as it has been shown to be highly selective towards atmospheric reactive species, including HOM. ${ }^{11,16} \mathrm{We}$ characterized the time evolution of the HOM under varying VOC precursor, $\mathrm{O}_{3}$ and $\mathrm{NO}_{\mathrm{x}}$ concentrations. Finally, tandem mass spectral $\left(\mathrm{MS}^{2}\right)$ analyses were performed to evaluate the possibility of obtaining chemical structure information of the compounds of interest.

\section{EXPERIMENTAL SECTION}

Materials. Limonene (Sigma-Aldrich, 97\% purity) and $\alpha$ pinene (Sigma-Aldrich, 98\% purity) were used as the VOC precursors. Nitric acid (Sigma-Aldrich, 65\% purity) was the reagent for ionization. All chemicals were used as received.

Analytical methods. The ozonolysis experiments were conducted at room temperature and atmospheric pressure in a flow tube reactor and in the absence of an $\mathrm{OH}$ scavenger. The reactor was a $\sim 18$-litres Pyrex glass tube $(12 \mathrm{~cm}$ i.d. $\times 158 \mathrm{~cm}$ length), which has been described in more detail previously. ${ }^{24}$ The total flow rate of synthetic air $\left(\mathrm{N}_{2} / \mathrm{O}_{2}\right.$ 80:20) was set at 15 liter per minute $(\mathrm{L} / \mathrm{min})$ giving an average residence time of 72 seconds. Ozone, generated by an ozone generator (Fisher Scientific, SOG-1) was continuously injected into the flow tube. For the experiments performed in the presence of nitrogen oxides $\left(\mathrm{NO}_{\mathrm{x}}\right)$, nitric oxide $(\mathrm{NO})$ was added into the flow tube reactor. The concentrations of ozone (initial concentration 40 $\mathrm{ppb}$ ) and $\mathrm{NO}$ (ranging from 0 to $1.8 \mathrm{ppb}$ ) were measured using a Thermo 49C and a Ecophysics CLD 88p equipped with a photolytic converter PLC 860, respectively. Concentrations of limonene varied from 0.4 to $2 \mathrm{ppm}$ and $\alpha$-pinene from 1 to 4 ppm, both measured using a proton transfer reaction time-offlight mass spectrometer (PTR-TOF 8000, Ionicon Analytik Gmbh).

For this study, a chemical ionization interface was specifically designed in order to be coupled with the Orbitrap (Figure S1). While the design of the CI inlet is based on that of Eisele and Tanner, ${ }^{25}$ we constructed a special connector flange as well as optimized the dimensions of the CI inlet for coupling to the Orbitrap. The Eisele-type inlet minimizes the wall losses through the use of coaxial sample and sheath flows $(10 \mathrm{~L} / \mathrm{min}$ and $30 \mathrm{~L} / \mathrm{min}$, respectively, used in this work), facilitating the characterization of (extremely) low-volatile and radical species. $\mathrm{NO}_{3}{ }^{-}$ions were generated by passing clean air $(10 \mathrm{~mL} / \mathrm{min})$ containing nitric acid through a soft X-ray photoionizer (Hamamatsu, L9491) and guided into the sample flow by an electric field. The sample molecules were charged by binding to the nitrate ion clusters $\left(\mathrm{HNO}_{3}\right)_{\mathrm{x}}\left(\mathrm{NO}_{3}{ }^{-}\right), \mathrm{x}=0-2$. The interaction time between $\mathrm{NO}_{3}{ }^{-}$ions and the sample was approximately $200 \mathrm{~ms}$.

The chemical composition of the gaseous species was retrieved in real time by a $\mathrm{Q}$ Exactive Orbitrap mass spectrometer (Thermo Scientific, US) which has been described elsewhere $^{26}$ and recently used for online measurements of atmospheric gases and particles. ${ }^{27,28}$ The Q Exactive has a high mass resolving power of 140000 (at $\mathrm{m} / \mathrm{z} 200$ ), allowing an accurate identification of a wide variety of species at a time resolution of $10 \mathrm{~s}$. The instrument was operated in negative mode, scanning from $\mathrm{m} / \mathrm{z} 50$ to 750 with a scan rate of 0.2 scans/s. External mass calibration of the Q Exactive mass spectrometer was performed using the traditional electrospray ionization source by using a $2 \mathrm{mM}$ sodium acetate solution. This approach provided a suite of negative adduct ions in the desired mass range. The high-resolution data were analyzed by XCalibur 2.2 (Thermo Scientific) software package to determine accurate formula and the abundance of the compounds of interest. The $\mathrm{MS}^{2}$ conditions were optimized to obtain the softer fragmentation and with a higher quadrupole isolation. $\mathrm{MS}^{2}$ analyses were performed at a normalized collision energy (NCE) of 10 and with a quadrupole isolation of $+/-0.15 \mathrm{~m} / \mathrm{z}$. To ensure an optimal detection of the fragment ion, mass spectra were averaged for $\sim 20$ minutes to increase the signal/noise ratio. The use of NCE automatically compensates for the mass dependency in the fragmentation processes occurring within the HCD (higher-energy collision dissociation cell). Without this automatic adjustment, too much energy would be applied to molecules having low $\mathrm{m} / \mathrm{z}$ (i.e., $\mathrm{m} / \mathrm{z}$ 200). As a result, the instrument automatically adjusted the collision energy. The actual collision energy for a Q-Exactive Orbitrap can be calculated as follow $\mathrm{CE}=(\mathrm{m} / \mathrm{z} / 500) \mathrm{x}$ NCE $\mathrm{x}$ $\mathrm{f}$ (charge of the ion).

\section{RESULTS AND DISCUSSION}

Characterization of OVOC by CI-Orbitrap. To highlight the features of this CI-Orbitrap, we focused our attention on the analysis of products from the ozonolysis of $\alpha$-pinene and limonene, as they constitute a major fraction of the global monoterpene emissions. ${ }^{29}$ In addition, both systems have been previously studied, ${ }^{8,30}$ which is a pivotal point to evaluate the performance of the CI-Orbitrap and validate our results. Using the CI-Orbitrap, we characterized the formation of HOM spanning from $\mathrm{m} / \mathrm{z} 250$ to 650 . HOM were detected as clusters with the nitrate $\left(\mathrm{NO}_{3}{ }^{-}\right)$ion. Figure 1 presents typical mass spectra obtained from the gas phase oxidation of both VOC with and without $\mathrm{NO}$. As previously reported, $\mathrm{NO}_{3}^{-}$-based chemistry is highly sensitive and selective towards $\mathrm{HOM}$, including monomers $\left(\mathrm{C}_{8-10} \mathrm{H}_{14-18} \mathrm{O}_{6-11}\right)$, organonitrates $\left(\mathrm{C}_{8-10} \mathrm{H}_{11-17} \mathrm{NO}_{6-11}\right)$ and dimers $\left(\mathrm{C}_{18-20} \mathrm{H}_{26-34} \mathrm{O}_{9-18}\right)$, formed from the ozonolysis of monoterpenes.

Analytical standards of gas-phase HOM remain lacking. Therefore, to estimate the sensitivity of the CI-Orbitrap, a calibration was inferred based on the expected molar yields of $\mathrm{HOM}$, as determined in earlier studies (citations). Ions from $\mathrm{m} / \mathrm{z}$ 300 to 650 were integrated, summed and normalized by the signal of the reagent ions (i.e., $\mathrm{NO}_{3}{ }^{-}, \mathrm{HNO}_{3} \mathrm{NO}_{3}{ }^{-},\left(\mathrm{HNO}_{3}\right)_{2} \mathrm{NO}_{3}{ }^{-}$ ). By using the molar yields reported in the literature ( $5 \%$ for $\alpha$ pinene and $10 \%$ for limonene $)^{8,11,30}$ and the amount of reacted VOC inferred by the variation in the ozone concentration we determined a theoretical concentration of the HOMs. We 
considered only the ozonolysis of the VOC, as $\mathrm{OH}$-initiated oxidation of limonene and $\alpha$-pinene produce much less HOM. ${ }^{9}$ Finally, to account for wall and particle losses we used a simple model to estimate a correction factor, which was evaluated at $50 \%$. Hence, we estimated calibration coefficients of $1.7 \times 10^{10}$ molecules $\mathrm{cm}^{-3} \mathrm{ncps}^{-1}$ and $2.0 \times 10^{10}$ molecules $\mathrm{cm}^{-3} \mathrm{ncps}^{-1}$, for $\alpha$-pinene and limonene ozonolysis, respectively. Considering the large uncertainties (i.e., $-50-+100 \%),{ }^{16,31}$ generated from scaling the sensitivity based on expected HOM yields, the sensitivity of the CI-Orbitrap (i.e., $1-3 \times 10^{10}$ molecules $\mathrm{cm}^{-3}$ $\mathrm{ncps}^{-1}$ ) seems to be similar to values reported for the CIAPiTOF. 8,19
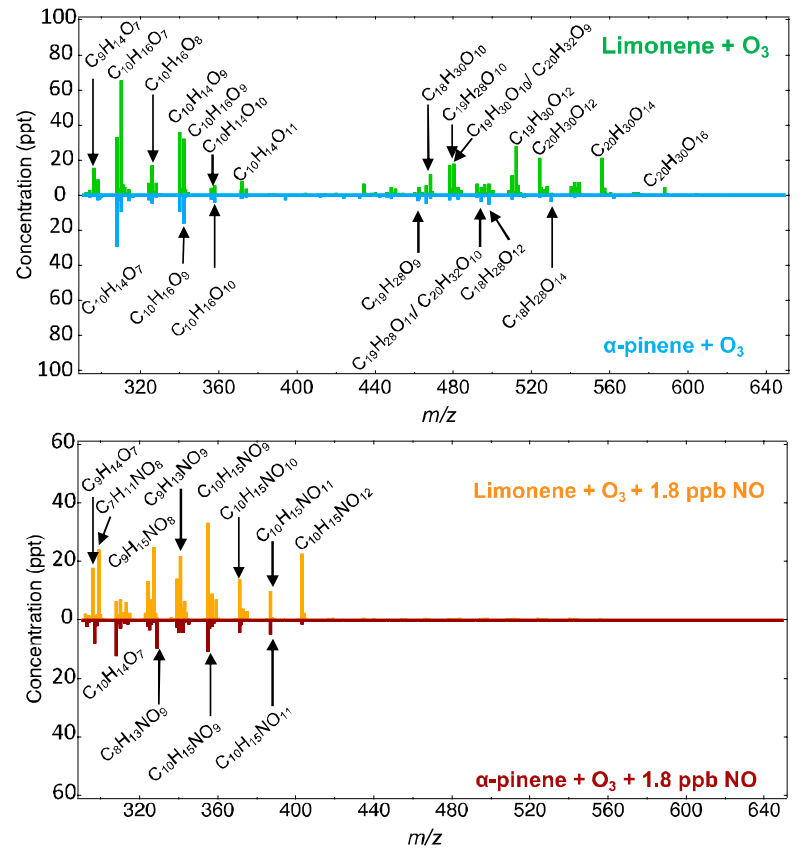

Figure 1. Mass spectra of HOM formed from limonene and $\alpha$ pinene ozonolysis without (upper) and with (lower) NO addition. HOM are detected as clusters with the nitrate $\left(\mathrm{NO}_{3}{ }^{-}\right)$ ion and measured by the CI-Orbitrap. Concentration is reported in parts per trillion (i.e., $2.46 \times 10^{7}$ molecule $\mathrm{cm}^{-3}$ ).

One main benefit of the CI-Orbitrap is the high mass resolving power, allowing unambiguous identification of the diverse products formed from a given reaction. As shown in Figure S2, we are now able to accurately distinguish organonitrates and peroxy radicals (e.g., $\mathrm{C}_{9} \mathrm{H}_{13} \mathrm{O}_{8} \mathrm{~N} / \mathrm{C}_{10} \mathrm{H}_{15} \mathrm{O}_{8}$ at $m / z 325.05344 / 325.06499$ and $\mathrm{C}_{9} \mathrm{H}_{13} \mathrm{O}_{10} \mathrm{~N} / \mathrm{C}_{10} \mathrm{H}_{15} \mathrm{O}_{10}$ at $m / z$ 357.04118 / 357.05382, respectively), which has often been impossible with typical CI-APi-TOF instruments with HTOF mass analyzers, and challenging even with LTOF mass analyzers. To compare the performance of the CI-Orbitrap to the CI-APi-TOF, we simulated the spectra of the latter at four ions, representing monomers $(\mathrm{m} / \mathrm{z} 342)$, organonitrate/peroxy radicals $(\mathrm{m} / \mathrm{z} 325$ and 357$)$ and dimers $(\mathrm{m} / \mathrm{z} 484)$. The CIOrbitrap data for these ions are presented in Figures 2 and S3, while the corresponding TOF data were generated using a mass resolving power of 5000 (Figure S3) and 10000 (Figure 2). It is evident that in most of these examples, the TOF instruments would struggle, while the CI-Orbitrap easily separated the ions of different elemental composition. Further, a larger mass resolving power (i.e., narrower peak) helps to decrease the detection limit. In other words, less signal is required to reach above the background noise level of the instrument, providing additional confidence in the quantification of the products observed in very low abundance.

Using in-source collision-induced dissociation (CID), which corresponds to an increase in the DC offset voltages in the ion optics of the flatapole, ${ }^{32}$ we probed the clustering strength of the $\mathrm{HOM}{ }^{*} \mathrm{NO}_{3}{ }^{-}$adducts. Similar approaches have been performed using iodide CIMS and provided crucial information on the ionization efficiency of the instrument. ${ }^{31,33}$ As reported in Figure S4, the in-source CID experiments revealed that the least oxidized $\mathrm{C}_{10}$-monomers exhibited the weakest binding energies, which is consistent with the low detection efficiency of such species. ${ }^{16}$ Interestingly, the dimers showed very strong binding energies, suggesting that such products are unlikely to undergo declustering in most mass spectrometers.
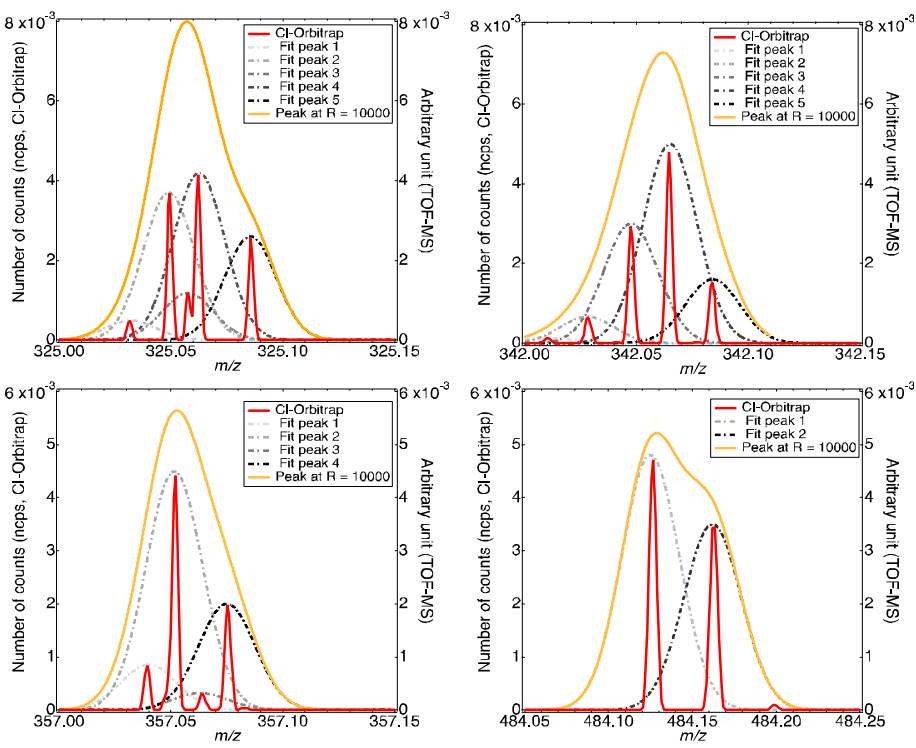

Figure 2. Mass spectra (red) of different HOM, at $\mathrm{m} / \mathrm{z} 325,342$, 357 and 484, measured by a nitrate CI-Orbitrap during limonene ozonolysis. Peak assignments are shown in Figure S2. The orange trace represents the spectrum that would be observed using an instrument with mass resolving power of 10 000. Dashed lines stand for the fits of individual ions. The TOFMS signals represent synthetic data using arbitrary units and do not aim at matching the surface area measured using the CIOrbitrap.

As the exact structures of the HOM have never been determined, this brings large uncertainties in the formation pathways of HOM (e.g., dimer formation), as well as in their physicochemical properties (i.e., nature of the functional groups). ${ }^{15}$ For the first time, we performed $\mathrm{MS}^{2}$ analysis on HOM to identify structural features from molecular fragmentation. While we were able to perform $\mathrm{MS}^{2}$ analysis for all the compounds of interests, including radicals and organonitrates, we focus here on two $\mathrm{C}_{10}$-monomers. Prior to entering the HCD cell, ions were selected via the quadrupole mass filter using a $\mathrm{m} / \mathrm{z}$ range of $+/-0.15 \mathrm{~m} / \mathrm{z}$. $\mathrm{MS}^{2}$ spectra obtained at an NCE of 10 (i.e., the lowest collision energy) of $\mathrm{C}_{10} \mathrm{H}_{14} \mathrm{O}_{7}$ and $\mathrm{C}_{10} \mathrm{H}_{16} \mathrm{O}_{9}$, generated from the ozonolysis of limonene and $\alpha$-pinene are presented Figure 3.. As anticipated, the main fragment observed during $\mathrm{MS}^{2}$ analyses corresponds to a loss of $\mathrm{NO}_{3}^{-}$. However, we were able to observe other fragment ions and obtained two distinct finger print mass spectra for ions with identical elemental formulas, produced from the oxidation of two VOC. This means that with a $\mathrm{MS}^{2}$ mass spectral library, one could identify the precursors of 
measured HOM from e.g., atmospheric samples with several VOC. In addition, information related to the structure of the studied HOM can also be extracted. For instance, the loss of $\mathrm{HNO}_{3}$ yielding fragment ion $\mathrm{C}_{10} \mathrm{H}_{15} \mathrm{O}_{9}$ might indicate the presence of an acid functional group for $\mathrm{C}_{10} \mathrm{H}_{16} \mathrm{O}_{9}$ formed from $\alpha$-pinene ozonolysis, but not from limonene. Formation of deprotonated ions using $\mathrm{NO}_{3}$-ion based chemistry has already been observed for organic molecules with functionalized acid group. ${ }^{34}$ This suggests that $\mathrm{C}_{10} \mathrm{H}_{16} \mathrm{O}_{9}$ generated from the oxidation of limonene and $\alpha$-pinene, might be significantly different. ${ }^{35}$ Further studies are needed for a more in depth interpretation of the different fragment ions.
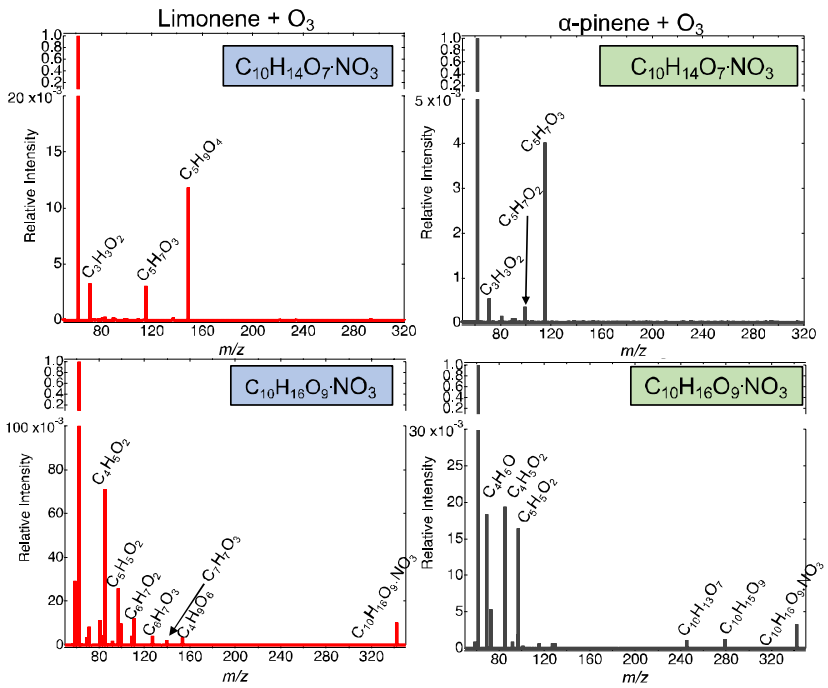

Figure 3. $\mathrm{MS}^{2}$ spectra of selected monomers $\left(\mathrm{C}_{10} \mathrm{H}_{14} \mathrm{O}_{7}\right.$ and $\mathrm{C}_{10} \mathrm{H}_{16} \mathrm{O}_{9}$ ) formed from the ozonolysis of limonene (left column) and $\alpha$-pinene (right column) in the absence of NO. $\mathrm{MS}^{2}$ spectra were obtained at an NCE of 10.

\section{CONCLUSION}

In this work we demonstrated, for the first time, the possibility of interfacing a CI to an ultrahigh-resolution mass spectrometer. We showed its ability in unambiguously resolving all ions measured by nitrate ion CIMS from the complex gas phase mixture generated from the oxidation of monoterpenes. Although this study focused on $\mathrm{NO}_{3}{ }^{-}$-based chemistry, other reagent ions including acetate, amine or bromine can be utilized in order to detect a wider range of OVOC and radical species in future studies. By using the $\mathrm{MS}^{2}$ feature of this new CI-Orbitrap, novel structural information of HOM can be acquired. This will greatly increase the obtainable molecular information compared to traditional TOF-based methods, and will help us to characterize the chemistry and, to a certain extent, the physicochemical properties (e.g., volatility) of the HOM. In summary, the development of this new analytical instrument can be a pivotal step forward for an accurate understanding of the formation and fate of atmospheric reactive organic species.

\section{ASSOCIATED CONTENT}

\section{Supporting Information}

Figure S1 depicts the design of the CI inlet. Figure S2 shows the mass spectra of ions at $\mathrm{m} / \mathrm{z} 310,325$ and 357 measured during the ozonolysis of limonene at different concentrations of NO. Figure S3 presents the peak fittings of different HOM using the CIOrbitrap and a CI-APi-TOF with a mass resolving power of 5000
Th/Th. Dashed lines stand for the fit of individual ions. Figure S4 presents the declustering experiments performed on HOM formed from $\alpha$-pinene ozonolysis. The Supporting Information is available free of charge on the ACS Publications website.

\section{AUTHOR INFORMATION}

\section{Corresponding Author}

* E-mail (M. R.): matthieu.riva@ircelyon.univ-lyon1.fr

\section{Author Contributions}

M.R. designed the experiment. M.R. F.B., and S.P. designed the CI inlet and the interface. F.B. realized all the mechanical parts. M.R., D.L., and S.T. performed the aerosol flow tube experiments. M.R. and M.E. analyzed the data and interpreted the compiled data set. M.R., M.E., and C.G. wrote the paper. All authors commented on the manuscript. The authors declare that they have no conflict of interest.

\section{ACKNOWLEDGMENT}

M.R. wishes to thank the French National program LEFE (Les Enveloppes Fluides et l'Environnement), and M.E. the ERC (grant 638703) and Academy of Finland (grants 317380 and 320094), for their financial support. The authors want to thank Abdelwahid Mellouki (ICARE-CNRS, Orleans) and his team for their technical support.

\section{REFERENCES}

(1) Albrecht, B. A. Aerosols, Cloud Microphysics, and Fractional Cloudiness. Science 1989, 245 (4923), 1227-1230. https://doi.org/10.1126/science.245.4923.1227.

(2) Rosenfeld, D.; Lohmann, U.; Raga, G. B.; O’Dowd, C. D.; Kulmala, M.; Fuzzi, S.; Reissell, A.; Andreae, M. O. Flood or Drought: How Do Aerosols Affect Precipitation? Science 2008, 321 (5894), 1309-1313. https://doi.org/10.1126/science.1160606.

(3) Gakidou, E.; Afshin, A.; Abajobir, A. A.; Abate, K. H.; Abbafati, C.; Abbas, K. M.; Abd-Allah, F.; Abdulle, A. M.; Abera, S. F.; Aboyans, V.; et al. Global, Regional, and National Comparative Risk Assessment of 84 Behavioural, Environmental and Occupational, and Metabolic Risks or Clusters of Risks, 1990-2016: A Systematic Analysis for the Global Burden of Disease Study 2016. The Lancet 2017, 390 (10100), 1345-1422. https://doi.org/10.1016/S01406736(17)32366-8.

(4) Jimenez, J. L.; Canagaratna, M. R.; Donahue, N. M.; Prevot, A. S. H.; Zhang, Q.; Kroll, J. H.; DeCarlo, P. F.; Allan, J. D.; Coe, H.; Ng, N. L.; et al. Evolution of Organic Aerosols in the Atmosphere. Science 2009, $326 \quad$ (5959), 1525-1529. https://doi.org/10.1126/science.1180353.

(5) Hallquist, M.; Wenger, J. C.; Baltensperger, U.; Rudich, Y.; Simpson, D.; Claeys, M.; Dommen, J.; Donahue, N. M.; George, C.; Goldstein, A. H.; et al. The Formation, Properties and Impact of Secondary Organic Aerosol: Current and Emerging Issues. Atmospheric Chemistry and Physics 2009, 9 (14), 5155-5236. https://doi.org/10.5194/acp-9-5155-2009.

(6) Glasius, M.; Goldstein, A. H. Recent Discoveries and Future Challenges in Atmospheric Organic Chemistry. Environmental Science \& Technology 2016, $50 \quad$ (6), 2754-2764. https://doi.org/10.1021/acs.est.5b05105.

(7) Goldstein, A. H.; Galbally, I. E. Known and Unexplored Organic Constituents in the Earth's Atmosphere. Environmental Science \& $\begin{array}{lllll}\text { Technology } & \mathbf{2 0 0 7}, & 41 & \text { (5), }\end{array}$ https://doi.org/10.1021/es072476p.

(8) Ehn, M.; Thornton, J. A.; Kleist, E.; Sipilä, M.; Junninen, H.; Pullinen, I.; Springer, M.; Rubach, F.; Tillmann, R.; Lee, B.; et al. A Large Source of Low-Volatility Secondary Organic Aerosol. Nature 2014, 506 (7489), 476-479. https://doi.org/10.1038/nature13032.

(9) Jokinen, T.; Sipilä, M.; Richters, S.; Kerminen, V.-M.; Paasonen, P.; Stratmann, F.; Worsnop, D.; Kulmala, M.; Ehn, M.; Herrmann, H.; 
et al. Rapid Autoxidation Forms Highly Oxidized $\mathrm{RO}_{2}$ Radicals in the Atmosphere. Angewandte Chemie International Edition 2014, 53 (52), 14596-14600. https://doi.org/10.1002/anie.201408566.

(10) Berndt, T.; Richters, S.; Kaethner, R.; Voigtländer, J.; Stratmann, F.; Sipilä, M.; Kulmala, M.; Herrmann, H. Gas-Phase Ozonolysis of Cycloalkenes: Formation of Highly Oxidized $\mathrm{RO}_{2}$ Radicals and Their Reactions with $\mathrm{NO}, \mathrm{NO}_{2}, \mathrm{SO}_{2}$, and Other $\mathrm{RO}_{2}$ Radicals. The Journal of Physical Chemistry A 2015, 119 (41), 10336-10348. https://doi.org/10.1021/acs.jpca.5b07295.

(11) Bianchi, F.; Kurtén, T.; Riva, M.; Mohr, C.; Rissanen, M. P.; Roldin, P.; Berndt, T.; Crounse, J. D.; Wennberg, P. O.; Mentel, T. F.; et al. Highly Oxygenated Organic Molecules (HOM) from Gas-Phase Autoxidation Involving Peroxy Radicals: A Key Contributor to Atmospheric Aerosol. Chemical Reviews 2019. https://doi.org/10.1021/acs.chemrev.8b00395.

(12) Crounse, J. D.; Nielsen, L. B.; Jørgensen, S.; Kjaergaard, H. G.; Wennberg, P. O. Autoxidation of Organic Compounds in the Atmosphere. The Journal of Physical Chemistry Letters 2013, 4 (20), 3513-3520. https://doi.org/10.1021/jz4019207.

(13) Tröstl, J.; Chuang, W. K.; Gordon, H.; Heinritzi, M.; Yan, C.; Molteni, U.; Ahlm, L.; Frege, C.; Bianchi, F.; Wagner, R.; et al. The Role of Low-Volatility Organic Compounds in Initial Particle Growth in the Atmosphere. Nature 2016, 533 (7604), 527-531. https://doi.org/10.1038/nature18271.

(14) Donahue, N. M.; Epstein, S. A.; Pandis, S. N.; Robinson, A. L. A Two-Dimensional Volatility Basis Set: 1. Organic-Aerosol Mixing Thermodynamics. Atmospheric Chemistry and Physics 2011, 11 (7), 3303-3318. https://doi.org/10.5194/acp-11-3303-2011.

(15) Kurtén, T.; Tiusanen, K.; Roldin, P.; Rissanen, M.; Luy, J.-N.; Boy, M.; Ehn, M.; Donahue, N. $\alpha$-Pinene Autoxidation Products May Not Have Extremely Low Saturation Vapor Pressures Despite High O:C Ratios. The Journal of Physical Chemistry A 2016, 120 (16), 2569-2582. https://doi.org/10.1021/acs.jpca.6b02196.

(16) Riva, M.; Rantala, P.; Krechmer, J. E.; Peräkylä, O.; Zhang, Y.; Heikkinen, L.; Garmash, O.; Yan, C.; Kulmala, M.; Worsnop, D.; et al. Evaluating the Performance of Five Different Chemical Ionization Techniques for Detecting Gaseous Oxygenated Organic Species. Atmospheric Measurement Techniques Discussions 2018, 1-39. https://doi.org/10.5194/amt-2018-407.

(17) Lee, B. H.; Lopez-Hilfiker, F. D.; Mohr, C.; Kurtén, T.; Worsnop, D. R.; Thornton, J. A. An Iodide-Adduct High-Resolution Time-ofFlight Chemical-Ionization Mass Spectrometer: Application to Atmospheric Inorganic and Organic Compounds. Environmental Science \& Technology 2014, 48 (11), 6309-6317. https://doi.org/10.1021/es500362a.

(18) Berndt, T.; Scholz, W.; Mentler, B.; Fischer, L.; Herrmann, H.; Kulmala, M.; Hansel, A. Accretion Product Formation from Self- and Cross-Reactions of RO ${ }_{2}$ Radicals in the Atmosphere. Angewandte Chemie International Edition 2018, 57 (14), 3820-3824. https://doi.org/10.1002/anie.201710989.

(19) Jokinen, T.; Sipilä, M.; Junninen, H.; Ehn, M.; Lönn, G.; Hakala, J.; Petäjä, T.; Mauldin, R. L.; Kulmala, M.; Worsnop, D. R. Atmospheric Sulphuric Acid and Neutral Cluster Measurements Using CI-APi-TOF. Atmospheric Chemistry and Physics 2012, 12 (9), 4117 4125. https://doi.org/10.5194/acp-12-4117-2012.

(20) Crounse, J. D.; McKinney, K. A.; Kwan, A. J.; Wennberg, P. O. Measurement of Gas-Phase Hydroperoxides by Chemical Ionization Mass Spectrometry. Analytical Chemistry 2006, 78 (19), 6726-6732. https://doi.org/10.1021/ac0604235.

(21) Cubison, M. J.; Jimenez, J. L. Statistical Precision of the Intensities Retrieved from Constrained Fitting of Overlapping Peaks in High-Resolution Mass Spectra. Atmospheric Measurement Techniques 2015, 8 (6), 2333-2345. https://doi.org/10.5194/amt-8-2333-2015.

(22) Stark, H.; Yatavelli, R. L. N.; Thompson, S. L.; Kimmel, J. R.; Cubison, M. J.; Chhabra, P. S.; Canagaratna, M. R.; Jayne, J. T.; Worsnop, D. R.; Jimenez, J. L. Methods to Extract Molecular and Bulk Chemical Information from Series of Complex Mass Spectra with Limited Mass Resolution. International Journal of Mass Spectrometry 2015, 389, 26-38. https://doi.org/10.1016/j.ijms.2015.08.011.
(23) Meija, J.; Caruso, J. A. Deconvolution of Isobaric Interferences in Mass Spectra. Journal of the American Society for Mass Spectrometry 2004, 15 (5), 654-658. https://doi.org/10.1016/j.jasms.2003.12.016.

(24) Aregahegn, K. Z.; Nozière, B.; George, C. Organic Aerosol Formation Photo-Enhanced by the Formation of Secondary Photosensitizers in Aerosols. Faraday Discussions 2013, 165, 123. https://doi.org/10.1039/c3fd00044c.

(25) Eisele, F. L.; Tanner, D. J. Measurement of the Gas Phase Concentration of $\mathrm{H}_{2} \mathrm{SO}_{4}$ and Methane Sulfonic Acid and Estimates of $\mathrm{H}_{2} \mathrm{SO}_{4}$ Production and Loss in the Atmosphere. Journal of Geophysical Research: Atmospheres 1993, 98 (D5), 9001-9010. https://doi.org/10.1029/93JD00031.

(26) Michalski, A.; Damoc, E.; Hauschild, J.-P.; Lange, O.; Wieghaus, A.; Makarov, A.; Nagaraj, N.; Cox, J.; Mann, M.; Horning, S. Mass Spectrometry-Based Proteomics Using Q Exactive, a HighPerformance Benchtop Quadrupole Orbitrap Mass Spectrometer. Molecular \& Cellular Proteomics 2011, 10 (9), M111.011015. https://doi.org/10.1074/mcp.M111.011015.

(27) Zuth, C.; Vogel, A. L.; Ockenfeld, S.; Huesmann, R.; Hoffmann, T. Ultrahigh-Resolution Mass Spectrometry in Real Time: Atmospheric Pressure Chemical Ionization Orbitrap Mass Spectrometry of Atmospheric Organic Aerosol. Analytical Chemistry 2018 90 (15), 8816-8823. https://doi.org/10.1021/acs.analchem.8b00671.

(28) Brüggemann, M.; Hayeck, N.; Bonnineau, C.; Pesce, S.; Alpert, P. A.; Perrier, S.; Zuth, C.; Hoffmann, T.; Chen, J.; George, C. Interfacial Photochemistry of Biogenic Surfactants: A Major Source of Abiotic Volatile Organic Compounds. Faraday Discussions 2017, 200, 59-74. https://doi.org/10.1039/C7FD00022G.

(29) Messina, P.; Lathière, J.; Sindelarova, K.; Vuichard, N.; Granier, C.; Ghattas, J.; Cozic, A.; Hauglustaine, D. A. Global Biogenic Volatile Organic Compound Emissions in the ORCHIDEE and MEGAN Models and Sensitivity to Key Parameters. Atmospheric Chemistry and Physics 2016, 16 (22), 14169-14202. https://doi.org/10.5194/acp-1614169-2016.

(30) Jokinen, T.; Berndt, T.; Makkonen, R.; Kerminen, V.-M.; Junninen, H.; Paasonen, P.; Stratmann, F.; Herrmann, H.; Guenther, A. B.; Worsnop, D. R.; et al. Production of Extremely Low Volatile Organic Compounds from Biogenic Emissions: Measured Yields and Atmospheric Implications. Proceedings of the National Academy of $\begin{array}{lllll}\text { Sciences } & \mathbf{2 0 1 5}, & 112 & \text { (23), } & 7123-7128 .\end{array}$ https://doi.org/10.1073/pnas.1423977112.

(31) Isaacman-VanWertz, G.; Massoli, P.; O’Brien, R.; Lim, C.; Franklin, J. P.; Moss, J. A.; Hunter, J. F.; Nowak, J. B.; Canagaratna, M. R.; Misztal, P. K.; et al. Chemical Evolution of Atmospheric Organic Carbon over Multiple Generations of Oxidation. Nature Chemistry 2018, 10 (4), 462-468. https://doi.org/10.1038/s41557-0180002-2.

(32) Perry, R. H.; Cooks, R. G.; Noll, R. J. Orbitrap Mass Spectrometry: Instrumentation, Ion Motion and Applications. Mass Spectrometry Reviews 2008, 27 (6), 661-699. https://doi.org/10.1002/mas.20186.

(33) Lopez-Hilfiker, F. D.; Iyer, S.; Mohr, C.; Lee, B. H.; D\&apos;Ambro, E. L.; Kurtén, T.; Thornton, J. A. Constraining the Sensitivity of Iodide Adduct Chemical Ionization Mass Spectrometry to Multifunctional Organic Molecules Using the Collision Limit and Thermodynamic Stability of Iodide Ion Adducts. Atmospheric Measurement Techniques 2016, 9 (4), 1505-1512. https://doi.org/10.5194/amt-9-1505-2016.

(34) Heinritzi, M.; Simon, M.; Steiner, G.; Wagner, A. C.; Kürten, A.; Hansel, A.; Curtius, J. Characterization of the Mass-Dependent Transmission Efficiency of a CIMS. Atmospheric Measurement Techniques 2016, 9 (4), 1449-1460. https://doi.org/10.5194/amt-91449-2016.

(35) Kroll, J. H.; Seinfeld, J. H. Chemistry of Secondary Organic Aerosol: Formation and Evolution of Low-Volatility Organics in the Atmosphere. Atmospheric Environment 2008, 42 (16), 3593-3624. https://doi.org/10.1016/j.atmosenv.2008.01.003. 
